\title{
Qualidade tecnológica e produtividade agroindustrial de cana-de- açúcar submetida a adubação com zinco
}

\section{Technological quality and agroindustrial yield of sugarcane subject to zinc fertilization}

\author{
Marcelo Carvalho Minhoto Teixeira Filho ${ }^{1 a^{*}}$; Salatiér Buzetti ${ }^{1 b}$; \\ Cássia Maria de Paula Garcia²; Cleiton Gredson Sabin Benett ${ }^{3}$; \\ Mateus Augusto de Carvalho Rodrigues ${ }^{4}$; Paulo Ricardo Maestrelo ${ }^{4}$; \\ Thiago de Souza Celestrino²; Rodolfo de Niro Gazola ${ }^{2}$
}

\begin{abstract}
Resumo
A qualidade tecnológica e a produtividade da cana-de-açúcar podem ser prejudicadas pela expansão da cultura para áreas de baixa fertilidade, onde geralmente se encontram baixos teores de zinco no solo. A deficiência deste nutriente pode ocasionar redução do perfilhamento, internódios mais curtos e colmos mais finos. Sendo assim, o objetivo deste trabalho foi avaliar o efeito de doses e fontes de zinco aplicadas no sulco de plantio, na qualidade tecnológica e produtividade agroindustrial da cana-de açúcar (cana-planta e $1^{a}$ cana-soca) cultivada num solo de textura arenosa com baixo teor de $\mathrm{Zn}$, na região Noroeste paulista. O experimento foi realizado num ARGISSOLO VERMELHO Eutroférrico, em área agrícola administrada pela Usina Vale do Paraná Açúcar e Álcool, em Suzanápolis - SP. O delineamento experimental utilizado na cana-planta e na $1^{a}$ cana-soca foi o de blocos ao acaso, com quatro repetições, num esquema fatorial (5x3), com cinco doses de zinco $\left(0 ; 2,5 ; 5,0 ; 7,5\right.$ e $\left.10,0 \mathrm{~kg} \mathrm{ha}^{-1}\right)$ e três fontes de zinco (FTE, quelato de $\mathrm{Zn}$ e sulfato de $\mathrm{Zn}$ ) aplicadas no sulco de plantio. Na $1^{\mathrm{a}}$ cana-soca, houve maiores porcentagens de POL da cana, POL do caldo e pureza do caldo quando do uso do quelato e sulfato de $\mathrm{Zn}$, e maior porcentagem de AR do caldo para o FTE e sulfato de Zn. A produtividade agroindustrial da cana-de-açúcar não foi afetada pelo aumento das doses de zinco. Baseado nos indicadores de qualidade tecnológica (POL, brix e ATR) da $1^{\text {a }}$ cana-soca, seria interessante a aplicação de 4,0 a 5,0 $\mathrm{kg} \mathrm{ha}^{-1} \mathrm{de} \mathrm{Zn}$ no sulco de plantio, na forma de quelato ou sulfato de $\mathrm{Zn}$.

Palavras-chave: Saccharum spp., fontes de zinco, micronutriente, ATR da cana, POL da cana
\end{abstract}

\begin{abstract}
The technological quality and yield of the sugarcane crop can be prejudiced by expansion of the crop to areas of low fertility, which usually present low zinc contents in the soil. The deficiency of this nutrient can result in the reduction of tillering, shorter internodes and thinner stem. Thus, the objective of this work was to evaluate the effect of doses and sources of zinc applied in the planting furrow, in
\end{abstract}

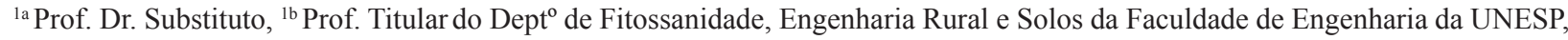
Campus de Ilha Solteira, C P 31, CEP 15385-000, Ilha Solteira, SP. ${ }^{16}$ Bolsistas em produtividade pelo CNPq. E-mail: mcmtf@ yahoo.com.br; sbuzetti@agr.feis.unesp.br

${ }^{2}$ Mestrando(s) em Agronomia, Sistemas de produção da Faculdade de Engenharia da UNESP, Campus de Ilha Solteira, SP. E-mail: cassiampg@yahoo.com.br; thiagomel_2@hotmail.com; rodolfodng@hotmail.com

${ }^{3}$ Dr. Bolsista DCR, Desenvolvimento Científico e Tecnológico Regional, FAPEG/CNPq, Goiânia, GO. E-mail: cbenett@hotmail. com

${ }^{4}$ Engenheiros Agrônomos pela Faculdade de Engenharia da UNESP, Campus de Ilha Solteira, SP. E-mail: mateusdinho@hotmail. com; paulomaestrelo@hotmail.com

* Autor para correspondência 
the technological quality and agroindustrial yield of the sugarcane (cane-plant and first cane-ratton) cultivated in a sandy texture soil with low zinc content, in Northwest of São Paulo state. The experiment was accomplished in an eutroferric Alfisol, in an agricultural area administered by Usina Vale do Paraná Sugar and Alcohol, in Suzanápolis - SP, Brazil. A randomized complete blocks design, with 4 repetitions, disposed in a factorial scheme 5x3, being: five doses of $\mathrm{Zn}\left(0 ; 2.5 ; 5.0 ; 7.5\right.$ e $\left.10.0 \mathrm{~kg} \mathrm{ha}^{-1}\right)$ and three sources of Zn (FTE, Zn chelate and Zn sulfate) applied in the planting furrow. In the first cane-ratton, there were larger percentages of sucrose concentration (pol cane and pol juice) and juice purity for the chelate and sulfate of Zn, and larger percentage of juice reducing sugars for the FTE and sulfate of Zn. The agroindustrial yield of the sugarcane was not affected by increasing the zinc doses. Based on the indicators of technological quality (sucrose concentration, brix cane and total recoverable sugar) of the first cane-ratton, would be interesting the application between 4.0 and $5.0 \mathrm{~kg} \mathrm{ha}^{-1}$ of $\mathrm{Zn}$ in the planting furrow, in the form of chelate or sulfate of $\mathrm{Zn}$.

Key words: Saccharum spp., zinc sources, micronutrient, sucrose concentration, total recoverable sugar

\section{Introdução}

Historicamente no setor sucroalcooleiro pouca atenção foi dada à resposta da cultura da canade-açúcar a aplicação de micronutrientes. Por isso, esta é uma prática pouco difundida entre as companhias agrícolas produtoras de cana-deaçúcar (FRANCO et al., 2009). Entretanto, a deficiência de micronutrientes pode causar sérios problemas ao desenvolvimento das culturas e queda de produtividade, visto que estes desempenham funções vitais no seu metabolismo.

Dentre os micronutrientes, o zinco ( $\mathrm{Zn}$ ) é importante pois potencializa a produção do hormônio de crescimento auxina, sintetase do triptofano e metabolismo de triptamina. Este elemento, também é constituinte do álcool desidrogenase, desidrogenase glutâmica, anidrase carbônica, entre outros compostos. O Zn se concentra nas zonas de crescimento devido à maior concentração auxínica (TAIZ; ZEIGER, 2004), portanto, seu principal efeito é no desenvolvimento e alongamento das partes jovens das plantas. A deficiência deste nutriente na cana-de-açúcar pode ocasionar redução do perfilhamento, internódios mais curtos e colmos mais finos (MALAVOLTA; VITTI; OLIVEIRA, 1997).

Na cana-de-açúcar, quando cultivada no estado de São Paulo, não é comum a visualização das deficiências de micronutrientes. Contudo, Orlando Filho, Rosseto e Casagrande (2001) alertam para o fato de que a cana-de-açúcar poderia apresentar, com freqüência, a chamada "fome oculta", situação em que não aparecem os sintomas de deficiência visuais, mas, os níveis presentes são insuficientes a ponto de levarem a redução da produtividade da cultura. Além disso, tal situação pode se agravar com a expansão da cultura para regiões com ambientes de produção (solo e clima) menos favoráveis, geralmente pastagens que não receberam adubação com zinco, sendo este o micronutriente mais carente devido ao pobre material de origem destes solos.

Korndörfer, Ribeiro e Andrade (1999) indicam a aplicação de zinco em cana-de-açúcar nas áreas deficientes do nutriente, especialmente em solos arenosos e com baixo teor de matéria orgânica, caso comum nas áreas de expansão da cultura no Noroeste do Estado de São Paulo. Dessa forma, a adubação com zinco em canaviais cultivados em solos com baixo teor deste nutriente pode ser importante para manter níveis adequados de zinco para a cultura, podendo assim, proporcionar maior crescimento dos internódios, aumentar o crescimento do topo da cana-de-açúcar e, consequentemente, aumentar o comprimento e produtividade de colmos. Entretanto, Franco et al. (2009), trabalhando com doses de $\mathrm{Zn}$ $\left(0,3\right.$ e $\left.6 \mathrm{~kg} \mathrm{ha}^{-1}\right)$ aplicadas ao solo como sulfato de zinco, não observaram aumento na produtividade de colmos, mas verificaram aumento nos teores de Brix, POL da cana e ATR da cana-planta. Por sua vez, Andrade et al. (1995), trabalhando com a aplicação de fritas e de fontes solúveis de boro, 
cobre e zinco (sulfato de $\mathrm{Zn}$ ), via solo, no sulco de plantio da variedade SP701143, cultivado em Latossolo Vermelho distrófico de textura média com baixo teor de $\mathrm{Zn}\left(0,3 \mathrm{mg} \mathrm{dm}^{-3}\right)$, verificaram que tanto a aplicação conjunta (fritas) como a aplicação isolada destes micronutrientes, não resultou em aumento dos teores foliares de $\mathrm{Zn}$, nos parâmetros tecnológicos e na produtividade de colmos.

Outro aspecto importante é determinar qual fonte deste micronutriente seria mais eficiente, tanto em cana-planta quanto em cana-soca. Visto que, a solubilidade e forma física (pó ou grânulo) das diversas fontes de micronutriente, bem como as condições de solo podem interagir de modo a resultar em maior ou menor efeito da adubação na correção de deficiências nutricionais (MORAES et al., 2004). Ressalta-se ainda que a maioria das pesquisas de adubação com zinco na cultura da cana-de-açúcar são antigas e foram realizadas apenas com o sulfato de zinco, portanto, há necessidade de mais estudos sobre o tema.

Neste contexto, o objetivo deste trabalho foi avaliar o efeito de doses e fontes de zinco aplicadas no sulco de plantio, na qualidade tecnológica e produtividade agroindustrial da cana-de açúcar (cana-planta e $1^{\text {a }}$ cana-soca) cultivada num solo de textura arenosa com baixo teor de $\mathrm{Zn}$, na região Noroeste paulista.

\section{Material e Métodos}

O experimento foi conduzido durante o período de 17 de março de 2008 a 7 de julho de 2010, na área agrícola administrada pela Usina Vale do Paraná Açúcar e Álcool, no município de Suzanápolis - SP, com coordenadas geográficas de $50^{\circ} 58^{\prime}$ de longitude Oeste e $20^{\circ} 32^{\prime}$ de latitude Sul e aproximadamente $335 \mathrm{~m}$ de altitude. O solo é classificado como ARGISSOLO VERMELHO Eutroférrico, de textura arenosa, segundo a Embrapa (2006), com valores de granulometria na profundidade de 0,0 -
0,20 m de 820, 56 e $124 \mathrm{~g} \mathrm{~kg}^{-1}$ de areia, silte e argila, respectivamente. Na profundidade de 0,20-0,40 m, os valores granulométricos foram 813,54 e $133 \mathrm{~g}$ $\mathrm{kg}^{-1}$ de areia, silte e argila, respectivamente.

O clima da região é Aw, de acordo com Köppen, definido como tropical úmido, com estação chuvosa no verão e seca no inverno. A temperatura média anual é de $23,5^{\circ} \mathrm{C}$, a precipitação pluvial média anual é de $1370 \mathrm{~mm}$ e a umidade relativa do ar média anual entre 70 e $80 \%$. Os valores médios mensais de precipitação pluvial $(\mathrm{mm})$, umidade relativa do ar $(\%)$ e temperaturas $\left({ }^{\circ} \mathrm{C}\right)$ máxima, média e mínima da área de cultivo durante a condução do experimento com cana-planta (safra 2008/2009) e com $1^{\text {a }}$ canasoca (safra 2009/2010) constam na Figura 1.

O delineamento estatístico foi o de blocos ao acaso, num esquema fatorial ( $5 \times 3)$, com cinco doses de zinco $\left(0 ; 2,5 ; 5,0 ; 7,5\right.$ e $\left.10,0 \mathrm{~kg} \mathrm{ha}^{-1}\right)$ e três fontes de zinco (sulfato de Zn, FTE de Zn (silicato em pó) e Zn quelatizado EDTA) aplicadas no sulco de plantio da cana-de-açúcar, com quatro repetições. As parcelas foram constituídas por 4 linhas de $5 \mathrm{~m}$ de comprimento e espaçadas por $1,5 \mathrm{~m}$, sendo as avaliações da cultura realizadas nas 2 linhas centrais da parcela.

Os tratamentos foram instalados em local onde antes havia pastagem de capim-braquiária, há pelo menos uma década. Primeiramente foi realizada a dessecação da pastagem com glifosate $(1,44$ $\mathrm{kg}$ do i.a. ha $\left.{ }^{-1}\right)$. O preparo do solo foi realizado com uma aração profunda, seguida de gradagem intermediária para incorporação do calcário $(0,20 \mathrm{~m}$ de profundidade) e de gradagem leve com aplicação do herbicida trifluralina ( $\left.2 \mathrm{~L} \mathrm{ha}^{-1}\right)$. Posteriormente, foi efetuada a sulcação do solo a $0,40 \mathrm{~m}$ de profundidade e a aplicação do inseticida fipronil (200 g do i.a. ha ${ }^{-1}$ ) no sulco de plantio. O sistema de plantio adotado foi manual (convencional), em que os colmos foram distribuídos e seccionados dentro dos sulcos de plantio, sendo colocados seis toletes com três gemas cada por metro de sulco. 
Figura 1. Precipitação pluvial (mm) mensal, umidade relativa do ar $(\%)$ mensal, temperaturas $\left({ }^{0} \mathrm{C}\right)$ máxima, média e mínima mensais durante a condução do experimento com cana-planta (A) na safra 2008/2009 e com cana-soca (B) na safra 2009/2010, em Suzanápolis - SP.

(A)

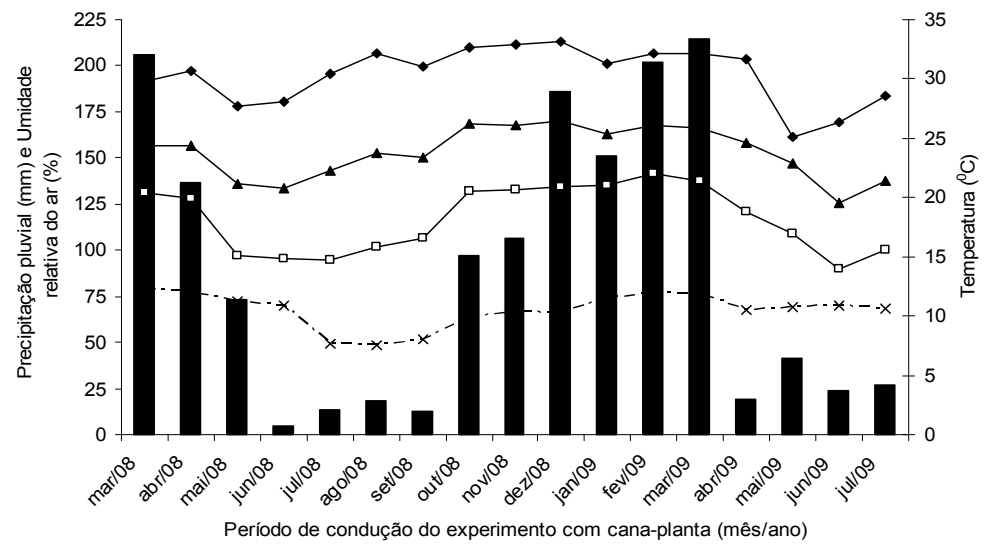

(B)

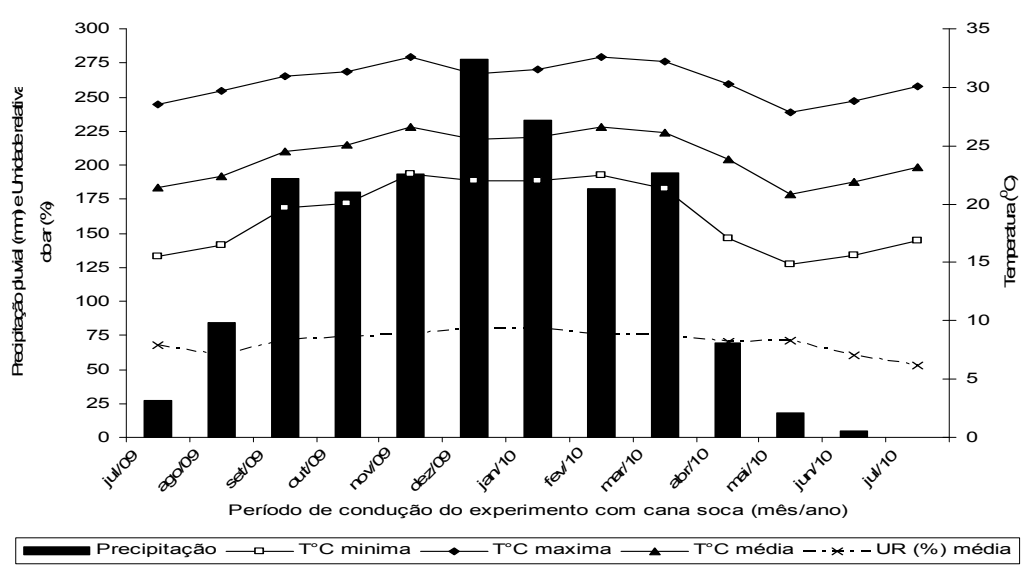

Fonte: Elaboração dos autores.

A variedade de cana-de-açúcar utilizada foi a RB867515, que apresenta ciclo tardio e é uma das variedades mais plantada no Estado de São Paulo. Esta variedade destaca-se por ser tolerante à seca, apresentar boa brotação de soqueira, mesmo colhida crua; porte alto, crescimento rápido com alta produtividade e alto teor de sacarose (HOFFMANN, 2008).
Os resultados da análise química do solo foram determinados antes da instalação do experimento (Tabela 1), segundo metodologia proposta por Raij et al. (2001), sendo constatados baixos teores de Zn no solo, conforme descrito em Raij, Cantarella e Camargo (1997). 
Tabela 1. Resultados da análise química do solo da área experimental. Suzanápolis-SP, 2007.

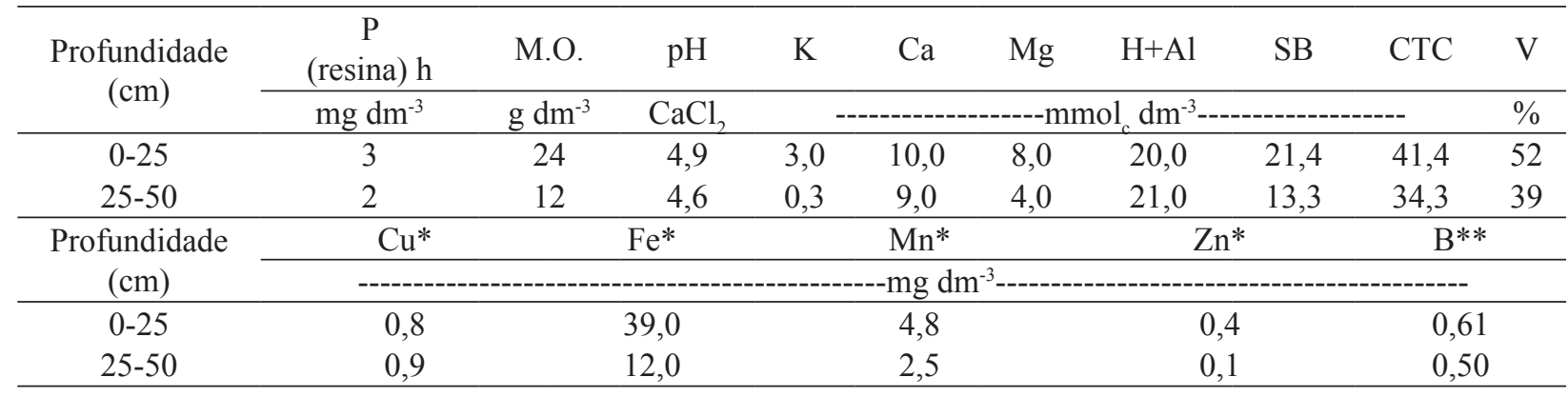

*Determinado em DTPA; **Água quente.

Fonte: Elaboração dos autores.

O solo da área experimental recebeu 30 dias antes do plantio da cultura a aplicação de $2 \mathrm{t} \mathrm{ha}^{-1}$ de calcário (302,3 $\mathrm{g} \mathrm{CaO} \mathrm{kg}^{-1}, 108,4 \mathrm{~g} \mathrm{MgO} \mathrm{kg}^{-1} \mathrm{e}$ $75 \%$ de PRNT). Na adubação de plantio aplicaramse $30 \mathrm{~kg} \mathrm{ha}^{-1}$ de $\mathrm{N}$ (ureia), $150 \mathrm{~kg} \mathrm{ha}^{-1} \mathrm{de}_{2} \mathrm{O}_{5}$ (super fosfato simples) e $120 \mathrm{~kg} \mathrm{ha}^{-1}$ de $\mathrm{K}_{2} \mathrm{O}$ (cloreto de potássio), igualmente para todos os tratamentos, baseada na análise do solo, e conforme a adubação utilizada pela própria usina. No dia 16 de outubro de 2009, foi realizada a adubação da $1^{\text {a }}$ soca da cana-de-açúcar nas entre linhas da cultura, sendo aplicados e incorporados ao solo $80 \mathrm{~kg} \mathrm{ha}^{-1}$ de $\mathrm{N}$ (uréia) e $60 \mathrm{~kg} \mathrm{ha}^{-1}$ de $\mathrm{K}_{2} \mathrm{O}$ (cloreto de potássio), conforme a adubação utilizada pela própria usina.

O controle de plantas daninhas foi realizado em ambos cultivos com a aplicação dos herbicidas diuron + hexazinone $\left(702+264\right.$ g do i.a. ha $\left.{ }^{-1}\right)$, em pós-emergência da cultura, sendo realizado 45 dias após o plantio da cana-planta e aos 55 dias após a colheita da cana-planta. Não houve a necessidade do controle de doenças e pragas da cultura e não foi constatado florescimento da cana-de-açúcar, em ambos os cultivos. A colheita da cana-planta (488 dias de ciclo) e da $1^{\text {a }}$ cana-soca (363 dias de ciclo) foi realizada manualmente e individualmente por unidade experimental, nos dias 08/07/2009 e 07/07/2010, respectivamente. Em seguida, o canavial foi colhido mecanicamente sem a queima prévia da cultura.
No momento da colheita da cultura foram separados 3 colmos industrializáveis por parcela, em seguida, estas amostras foram devidamente identificadas e posteriormente, levadas ao laboratório da Destilaria Vale do Paraná Açúcar e Álcool para a realização das análises de qualidade tecnológica da cana-de-açúcar, conforme o Conselho dos Produtores de Cana, Açúcar e Álcool do Estado de São Paulo (CONSECANA, 2006).

As análises realizadas na cana-planta e $1^{\mathrm{a}}$ canasoca foram: pureza do caldo da cana (\%), POL da cana (\%), POL do caldo (\%), fibra da cana (\%), brix da cana (\%), açúcares redutores (AR) do caldo (\%) e açúcar total recuperável (ATR) da cana (kg de açúcar $\mathrm{t}^{-1}$ de cana). Com base nestes resultados foram calculados a quantidade de ATR por hectare (t de açúcar ha-1) e a produtividade agroindustrial da cana-de-açúcar ( $\mathrm{t} \mathrm{ha}^{-1}$ de POL), sendo esta última avaliação, obtida através da multiplicação da produtividade de colmos com a porcentagem de POL da cana.

Os dados foram submetidos à análise de variância (teste F) e as médias comparadas pelo teste de Tukey a 5\% de probabilidade para fontes de $\mathrm{Zn}$ e ajustadas a equações de regressão para o efeito das doses de Zn. Para análise estatística foi utilizado, o programa SISVAR (FERREIRA, 2008). 


\section{Resultados e Discussão}

$\mathrm{Na}$ Tabela 2, verifica-se que as fontes de $\mathrm{Zn}$ (FTE, quelato e sulfato) aplicadas no sulco de plantio da cultura não diferiram significativamente apenas para o brix da cana-de-açúcar, em ambos cultivos. Sendo assim, as fontes de Zn não afetaram a porcentagem de sólidos solúveis totais (açúcares e não açúcares). Com relação a pureza do caldo da cana-de-açúcar, que quanto maior a porcentagem melhor é qualidade da matéria-prima, houve diferença entre as fontes de Zn somente para $1^{a}$ canasoca, sendo que o quelato de $\mathrm{Zn}$ proporcionou maior pureza, apesar deste não diferir significativamente do sulfato de Zn. Entretanto, é importante destacar que as porcentagens de pureza do caldo obtidas em cana-planta e $1^{\mathrm{a}}$ cana-soca estiveram sempre acima de $85 \%$, valor limite recomendado para um bom resultado desta avaliação, segundo Ripoli e Ripoli (2004).

Tabela 2. Médias, teste de Tukey e coeficientes de variação (C.V.) referentes a pureza do caldo, POL da cana, POL do caldo, fibra e brix da cana-de-açúcar (cana-planta e $1^{\mathrm{a}}$ cana-soca), em função de fontes e doses de zinco. Suzanápolis - SP, 2008/2009 e 2009/2010.

\begin{tabular}{|c|c|c|c|c|c|}
\hline & Pureza do caldo & $\begin{array}{c}\text { POL } \\
\text { da cana }\end{array}$ & $\begin{array}{c}\text { POL } \\
\text { do caldo }\end{array}$ & $\begin{array}{c}\text { Fibra } \\
\text { da cana }\end{array}$ & $\begin{array}{c}\text { Brix } \\
\text { da cana }\end{array}$ \\
\hline & \multicolumn{5}{|c|}{ - } \\
\hline & & & Cana- & & \\
\hline \multicolumn{6}{|l|}{ Fontes de $\mathrm{Zn}$} \\
\hline FTE & 88,56 & 78,05 & 18,84 & $12,80 \mathrm{~b}$ & 21,28 \\
\hline Quelato de Zn & 89,90 & 79,38 & 19,13 & $12,86 \mathrm{ab}$ & 21,33 \\
\hline Sulfato de $\mathrm{Zn}$ & 88,66 & 80,40 & 19,33 & $13,24 \mathrm{a}$ & 21,60 \\
\hline D.M.S. (5\%) & 2,27 & 2,39 & 0,51 & 0,41 & 0,51 \\
\hline Média geral & 89,04 & 79,28 & 19,10 & 12,97 & 21,40 \\
\hline \multirow[t]{2}{*}{ C.V. $(\%)$} & 3,32 & 3,92 & 3,50 & 4,10 & 3,11 \\
\hline & \multicolumn{5}{|c|}{$1^{a}$ Cana-soca } \\
\hline \multicolumn{6}{|l|}{ Fontes de $\mathrm{Zn}$} \\
\hline FTE & $87,07 \mathrm{~b}$ & $79,38 \mathrm{~b}$ & $18,97 \mathrm{~b}$ & 12,46 & 21,81 \\
\hline Quelato de $\mathrm{Zn}$ & $88,85 \mathrm{a}$ & $81,57 \mathrm{a}$ & $19,48 \mathrm{a}$ & 12,48 & 21,92 \\
\hline Sulfato de Zn & $88,48 \mathrm{ab}$ & $81,51 \mathrm{a}$ & 19,46 a & 12,35 & 22,01 \\
\hline D.M.S. $(5 \%)$ & 1,54 & 1,81 & 0,40 & 0,32 & 0,54 \\
\hline Média geral & 88,13 & 80,82 & 19,30 & 12,43 & 21,91 \\
\hline C.V. (\%) & 2,27 & 2,91 & 2,70 & 3,35 & 3,19 \\
\hline
\end{tabular}

Médias seguidas de letra iguais, na coluna, não diferem entre si pelo teste de Tukey, em nível de $5 \%$ de probabilidade. ${ }^{\text {ns Não }}$ significativo pela análise de regressão.

Fonte: Elaboração dos autores.

As fontes de $\mathrm{Zn}$ diferiram significativamente quanto a POL da cana e POL do caldo para $1^{\text {a }}$ canasoca (Tabela 2), sendo que em ambas avaliações, o quelato e sulfato de $\mathrm{Zn}$ foram superiores ao FTE de $\mathrm{Zn}$. Portanto, estas fontes de $\mathrm{Zn}$ proporcionaram maior porcentagem aparente de sacarose, em peso, na cana e no caldo da cana. De acordo com Ripoli e Ripoli (2004), os resultados de POL do caldo da cana-de-açúcar encontrados foram todos satisfatórios, já que ficaram acima de 14\%.
Quanto a porcentagem de fibra da cana, verificou-se diferença significativa entre as fontes de $\mathrm{Zn}$ apenas para cana-planta, sendo que o sulfato de $\mathrm{Zn}$ proporcionou a maior porcentagem de fibra, apesar deste não diferir do quelato de $\mathrm{Zn}$ (Tabela 2), o que pode ser devido a maior solubilidade destas fontes. Contudo, ressalta-se que os valores obtidos neste experimento, estão dentro da faixa considerada adequada para fibra da cana (de 11 a 13\%), de acordo com Ripoli e Ripoli (2004). Quanto 
mais alta a porcentagem de fibra da cana, menor será a eficiência da extração da moenda. Já a baixa porcentagem de fibra pode provocar acamamento e, também quebra de ponteiros pela ação dos ventos (SEGATO; ALONSO; LAROSA, 2006).

Com relação as doses de $\mathrm{Zn}$, estas não afetaram a pureza do caldo e a fibra da cana, nos dois cultivos da cana-de-açúcar (Tabela 2). Estes resultados são semelhantes aos relatados por Andrade et al. (1995), Korndörfer et al. (1995) e Farias et al. (2009). Porém, Marinho e Albuquerque (1981) verificaram efeito significativo da aplicação de Zn na pureza do caldo da cana-de-açúcar, em sete experimentos conduzidos em solos de tabuleiro em Alagoas, quando os teores deste micronutriente estavam inferiores a $0,5 \mathrm{mg} \mathrm{dm}^{-3}$.

APOL da cana e POL do caldo foram influenciadas pelas doses de $\mathrm{Zn}$ apenas na $1^{\mathrm{a}}$ cana-soca, ajustandose a funções quadráticas, com o ponto de máxima POL da cana e POL do caldo sendo alcançado com a estimativa de aplicação de $4,37 \mathrm{~kg} \mathrm{ha}^{-1}$ de Zn (Figuras 2 e 3). As respostas destes indicadores de qualidade tecnológica da cana-de-açúcar à adubação com zinco, descritas na literatura, são muito variáveis. Franco et al. (2009), trabalhando com doses de $\mathrm{Zn}\left(0,3\right.$ e $\left.6 \mathrm{~kg} \mathrm{ha}^{-1}\right)$ aplicadas ao solo, na forma de sulfato de zinco dissolvido em água (200 L ha ${ }^{-1}$ ) e 90 dias após o plantio da cultura, também observaram aumento significativo na porcentagem de POL da cana. Resultado semelhante foi observado por Marinho e Albuquerque (1981). Entretanto, Andrade et al. (1995), trabalhando com a aplicação de fritas e de sulfato de $\mathrm{Zn}$, via solo, no sulco de plantio da variedade SP701143, cultivado em Latossolo Vermelho distrófico com baixo teor de Zn $\left(0,3 \mathrm{mg} \mathrm{dm}^{-3}\right)$, verificaram que tanto a aplicação conjunta (fritas) como a aplicação isolada de zinco, não resultou em aumento deste parâmetro. Além disso, estes autores também não observaram efeito residual desta adubação na $1^{\text {a }}$ cana-soca. Farias et al. (2009), avaliando a qualidade industrial de canade-açúcar (variedade SP791011) sob irrigação e a aplicação de doses de $\mathrm{Zn}\left(0,1,2,3\right.$ e $\left.4 \mathrm{~kg} \mathrm{ha}^{-1}\right)$, em solo do Tabuleiro Costeiro paraibano, também não observaram influência da adubação com zinco sobre a POL da cana.

Figura 2. Equação de regressão referente a POL da cana-de-açúcar ( $1^{\mathrm{a}}$ cana-soca) em função de doses de Zn. Suzanápolis - SP, 2009/2010.

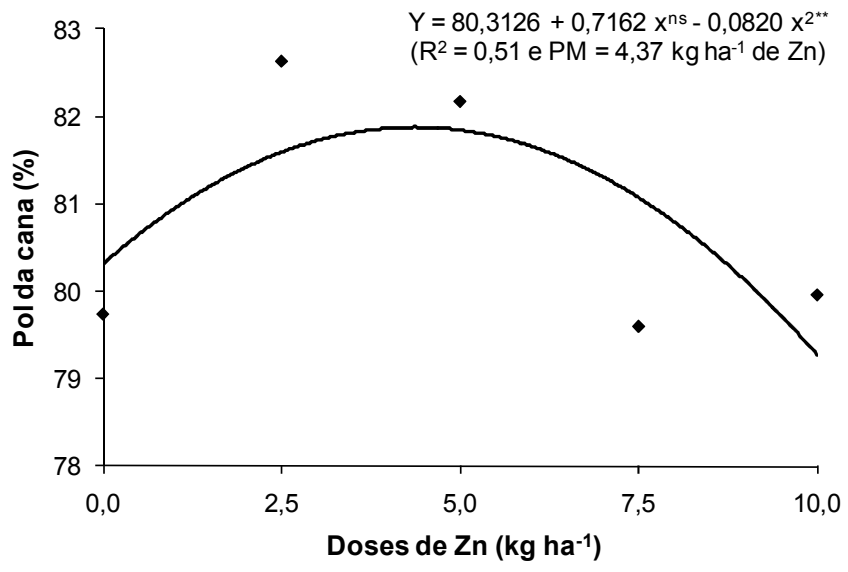

Fonte: Elaboração dos autores. 
Figura 3. Equação de regressão referente a POL do caldo da cana-de-açúcar ( $1^{\text {a }}$ cana-soca) em função de doses de Zn. Suzanápolis - SP, 2009/2010.

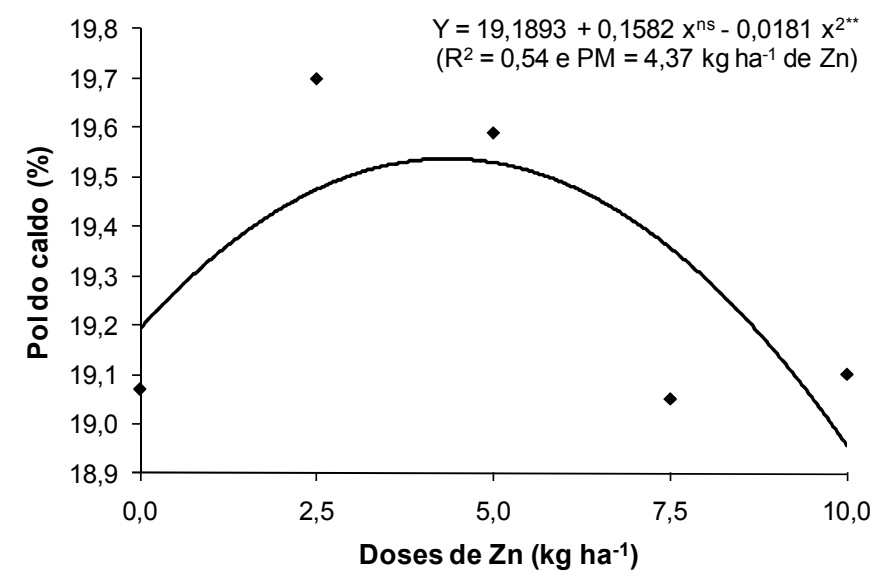

Fonte: Elaboração dos autores.

$\mathrm{Na}$ Figura 4, constata-se que as doses de $\mathrm{Zn}$ também influenciaram significativamente o brix da $1^{\text {a }}$ cana-soca, ajustando-se a função quadrática com o ponto de máximo brix da cana sendo alcançado com a estimativa de aplicação de 4,25 $\mathrm{kg} \mathrm{ha}^{-1}$ de Zn. Isto mostra que a adubação com zinco pode elevar a porcentagem de sólidos solúveis totais (açúcares e não açúcares). Franco et al. (2009), também constataram aumento significativo na porcentagem de brix da cana. Por outro lado, Andrade et al. (1995), Korndörfer et al. (1995) e Farias et al. (2009) não verificaram efeito da adubação com zinco no brix da cana.

Figura 4. Equação de regressão referente ao Brix da cana-de-açúcar ( $1^{\mathrm{a}}$ cana-soca) em função de doses de $\mathrm{Zn}$. Suzanápolis - SP, 2009/2010.

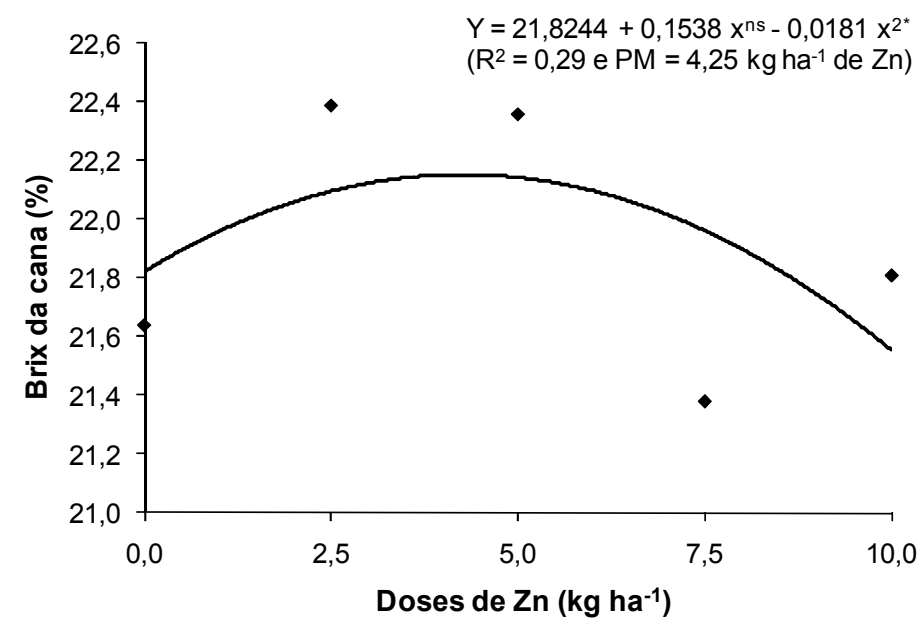

Fonte: Elaboração dos autores. 
As fontes de Zn (FTE, quelato e sulfato) aplicadas no sulco de plantio da cultura não diferiram significativamente para a quantidade de ATR por hectare e produtividade agroindustrial da cana-deaçúcar, nos dois cultivos (Tabela 3). Com relação a quantidade de AR do caldo da cana-de-açúcar, que afeta diretamente a pureza do caldo, houve diferença entre as fontes de $\mathrm{Zn}$ somente para $1^{\mathrm{a}}$ cana-soca, sendo que o FTE de Zn apresentou maior quantidade de açúcares redutores (glicose e frutose) no caldo, apesar deste não diferir significativamente do sulfato de Zn (Tabela 3). Contudo, ressalta-se que os valores médios de AR do caldo em ambos cultivos, foram satisfatórios, pois ficaram abaixo de $0,8 \%$, que é o valor limite recomendado para esta característica, de acordo com Ripoli e Ripoli (2004). Quanto a quantidade de ATR da cana, constatou-se diferença significativa entre as fontes de $\mathrm{Zn}$ apenas para a $1^{\text {a }}$ cana-soca, sendo que o sulfato e o quelato de Zn proporcionaram maior quantidade de açúcar total recuperável (ATR) da cana, em relação ao FTE de Zn (Tabela 3).

Tabela 3. Médias, teste de Tukey e coeficientes de variação (C.V.) referentes ao AR do caldo, ATR da cana, ATR por hectare e produtividade agroindustrial da cana-de-açúcar (cana-planta e $1^{\mathrm{a}}$ cana-soca), em função de fontes e doses de zinco. Suzanápolis - SP, 2008/2009 e 2009/2010.

\begin{tabular}{|c|c|c|c|c|}
\hline & $\begin{array}{c}\text { AR } \\
\text { do caldo } \\
(\%)\end{array}$ & $\begin{array}{l}\text { ATR da cana } \\
\text { (kg de açúcar } \\
\left.\mathrm{t}^{-1} \text { de cana }\right)\end{array}$ & $\begin{array}{l}\text { ATR por hectare } \\
\left.\text { (t de açúcar ha }{ }^{-1}\right)\end{array}$ & $\begin{array}{l}\text { Produtividade } \\
\text { agroindustrial } \\
\left(\mathrm{t} \mathrm{ha}^{-1} \mathrm{de} \text { Pol }\right)\end{array}$ \\
\hline & \multicolumn{4}{|c|}{ Cana-planta } \\
\hline \multicolumn{5}{|l|}{ Fontes de $\mathrm{Zn}$} \\
\hline FTE & 0,66 & 154,46 & 13,47 & 16,43 \\
\hline Quelato de $\mathrm{Zn}$ & 0,60 & 156,46 & 13,75 & 16,83 \\
\hline Sulfato de $\mathrm{Zn}$ & 0,69 & 157,07 & 13,61 & 16,76 \\
\hline D.M.S. $(5 \%)$ & 0,13 & 4,20 & 1,36 & 1,68 \\
\hline Média geral & 0,65 & 156,00 & 13,60 & 16,67 \\
\hline C.V. $(\%)$ & 26,81 & 3,51 & 13,00 & 13,11 \\
\hline \multirow{2}{*}{\multicolumn{5}{|c|}{$1^{\text {a } \text { Cana-soca }}$}} \\
\hline & & & & \\
\hline FTE & $0,65 \mathrm{a}$ & $156,76 \mathrm{~b}$ & 16,42 & 20,19 \\
\hline Quelato de $\mathrm{Zn}$ & $0,59 \mathrm{~b}$ & $160,33 \mathrm{a}$ & 17,90 & 22,24 \\
\hline Sulfato de Zn & $0,61 \mathrm{ab}$ & $160,62 \mathrm{a}$ & 16,49 & 20,40 \\
\hline D.M.S. (5\%) & 0,05 & 2,88 & 2,22 & 2,83 \\
\hline Média geral & 0,62 & 159,24 & 16,93 & 20,94 \\
\hline C.V. $(\%)$ & 11,11 & 2,35 & 17,05 & 17,57 \\
\hline
\end{tabular}

Médias seguidas de letra iguais, na coluna, não diferem entre si pelo teste de Tukey, em nível de 5\% de probabilidade. ${ }^{\text {ns Não }}$ significativo pela análise de regressão.

Fonte: Elaboração dos autores.

As doses de Zn não influenciaram a porcentagem de AR do caldo, a quantidade ATR por hectare e a produtividade agroindustrial da cana-de-açúcar, tanto em cana-planta como na $1^{\mathrm{a}}$ cana-soca (Tabela 3). Por sua vez, Franco et al. (2009) verificaram aumento na porcentagem de AR do caldo com o incremento das doses de Zn. Entretanto, a quantidade de ATR da cana foi influenciada significativamente pelas doses de Zn na $1^{\mathrm{a}}$ cana-soca, ajustando-se a função quadrática com o ponto de máximo ATR da cana sendo alcançado com a estimativa de aplicação de 4,00 $\mathrm{kg} \mathrm{ha}^{-1}$ de Zn (Figura 5). Observou-se assim, 
com a aplicação desta dose ótima $\left(4,0 \mathrm{~kg} \mathrm{ha}^{-1}\right.$ de $\mathrm{Zn}$ ) um aumento de $4 \mathrm{~kg}$ de açúcar por tonelada de cana em relação a testemunha $\left(0,0 \mathrm{~kg} \mathrm{ha}^{-1} \mathrm{de}\right.$ Zn). Portanto, a adubação com zinco pode elevar a quantidade de açúcar total recuperável (ATR) contido na cana-de-açúcar. Isto é importante, pois o atual modelo de pagamento da cana é denominado sistema de remuneração da tonelada de cana pela qualidade - sistema CONSECANA (SEGATO; ALONSO; LAROSA, 2006).

Figura 5. Equação de regressão referente ao ATR da cana-de-açúcar ( $1^{\mathrm{a}}$ cana-soca) em função de doses de Zn. Suzanápolis - SP, 2009/2010.

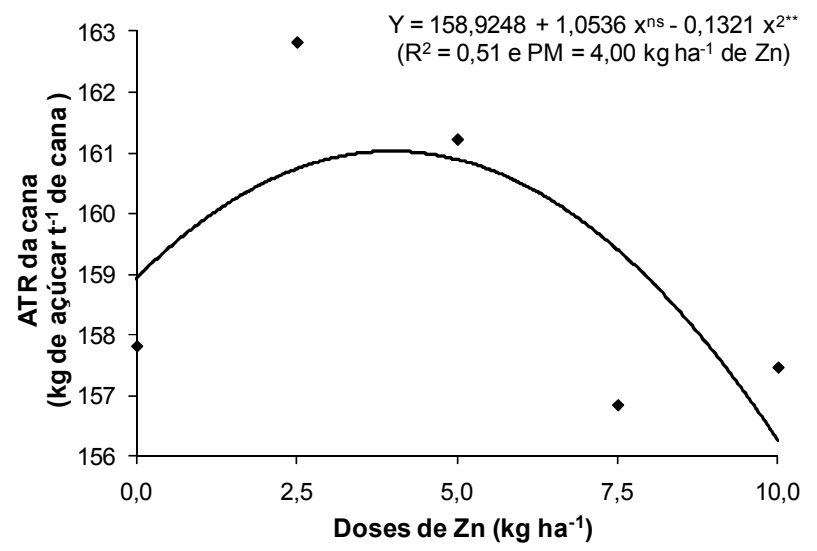

Fonte: Elaboração dos autores.

Franco et al. (2009) também relataram aumento significativo na quantidade de ATR da cana-planta (variedade SP813250), em relação a testemunha, resultando em maior rendimento de açúcar por área, com margem de contribuição da ordem de $\mathrm{R} \$ 500,00$ por hectare com a aplicação de $3 \mathrm{~kg} \mathrm{ha}^{-1}$ de $\mathrm{Zn}$. Entretanto, Andrade et al. (1995), Korndörfer et al. (1995) e Farias et al. (2009) não verificaram efeito da adubação com zinco neste importante parâmetro. Por sua vez, Wang et al. (2005), averiguando a resposta da cana-de-açúcar à aplicação de sulfato de zinco no solo $\left(0 ; 4,4 ; 8,9 ; 17,9\right.$ e $33,8 \mathrm{~kg} \mathrm{ha}^{-1}$ de $\mathrm{Zn}$ ), no estado da Lousiana, Estados Unidos da América, observaram incremento na produtividade de açúcar (variedade LCP 85-384), em um solo ácido e outro de origem cálcaria, ambos com baixos teores de Zn. Entretanto, Azeredo e Bolsanello (1981), pesquisando a aplicação de sulfato de zinco $\left(8,75 \mathrm{~kg} \mathrm{ha}^{-1}\right.$ de $\left.\mathrm{Zn}\right)$ no sulco de plantio ou via foliar
(1\% de Zn em solução, aplicados ao 90 dias após o plantio), em oito experimentos desenvolvidos em quatro locais na região Sudeste, e cultivados na presença e ausência de calagem, não constataram resposta à adição de Zn para o ATR da cana-planta (variedade CB453), em nenhum dos experimentos.

Uma hipótese relatada por Franco et al. (2009), que também explica os resultados positivos obtidos para os indicadores de qualidade tecnológica (POL da cana, POL do caldo, brix da cana e ATR da cana) da $1^{\text {a }}$ cana-soca em resposta à aplicação de doses de Zn (Tabelas 2 e 3), é que, este efeito poderia ser função do Zn no metabolismo do fitohormônio AIA. Nesse caso, o efeito residual da aplicação de Zn pode ter estimulado o crescimento vegetal nos estádios iniciais de desenvolvimento da cultura, visto que ocorreram consideráveis precipitações pluviais neste período (Figura $1 \mathrm{~B}$ ), fazendo com que a $1^{\text {a }}$ cana-soca completasse seu ciclo em 
menor tempo, e assim, como efeito secundário, proporcionasse uma melhora destes indicadores de qualidade tecnológica na colheita do experimento. Além disso, Dechen, Haag e Carmello (1991) explicaram que a maior absorção de Zn no início da cultura, deve-se a esse elemento fazer parte de sistemas enzimáticos, regulando o metabolismo de carboidratos, fosfatos e proteínas além da formação de auxinas, RNA e ribossomos, fatores essenciais na regulação do crescimento da planta.

\section{Conclusões}

A qualidade tecnológica da cana-planta não foi influenciada pelo incremento das doses de zinco.

$\mathrm{Na} 1^{\mathrm{a}}$ cana-soca, houve maiores porcentagens de POL da cana, POL do caldo e pureza do caldo quando do uso do quelato e sulfato de $\mathrm{Zn}$, e maior porcentagem de AR do caldo para o FTE e sulfato de Zn.

A produtividade agroindustrial da cana-de-açúcar não foi afetada pelo aumento das doses de zinco, independentemente da fonte deste micronutriente utilizada.

Baseado nos indicadores de qualidade tecnológica (POL, Brix e ATR) da $1^{\mathrm{a}}$ cana-soca, seria interessante a aplicação de 4,0 a $5,0 \mathrm{~kg} \mathrm{ha}^{-1}$ de $\mathrm{Zn}$ no sulco de plantio, na forma de quelato ou sulfato de Zn.

\section{Agradecimentos}

À FAPESP pelo apoio financeiro e concessão da bolsa de doutorado do primeiro autor (Processo 2007/07063-7).

\section{Referências}

ANDRADE, L. A. B.; CASAGRANDE, A. A.; VITTI, G. C.; PERECIN, D. Efeitos das aplicações de fritas e de fontes solúveis de boro, cobre e zinco, via solo, na cultura de cana-de-açúcar (Saccharum spp.), variedade SP701143. STAB - Açúcar, Álcool e Subprodutos, Piracicaba, v. 13 , n. 5 , p. 21-27, 1995.

AZEREDO, D. F.; BALSANELLO, J. Efeito de micronutrientes na produção e na qualidade da cana-deaçúcar no Rio de Janeiro, Espirito Santo e Minas Gerais (Zona da Mata). Estudo preliminar. Brasil Açucareiro, Rio de Janeiro, v. 3, n. 9, p. 9-17, 1981.

CONSECANA - Conselho dos produtores de cana-deaçúcar, açúcar e álcool do estado de São Paulo. Manual de instruções. 5. ed. Piracicaba: Consecana, 2006. 112 p.

DECHEN, A. R.; HAAG, H. P.; CARMELLO, Q. A. de C. Funções dos micronutrientes nas plantas. In: FERREIRA, M. E.; CRUZ, M. C. P. (Coord.). Micronutrientes na agricultura. Piracicaba: Potafos/CNPq, 1991. p. 65-78.

EMPRESA BRASILEIRA DE PESQUISA AGROPECUÁRIA - EMBRAPA. Sistema brasileiro de classificação de solos. 2. ed. Rio de Janeiro: EMBRAPA/ CNPSo, 2006. 306 p.

FARIAS, C. H. de A.; FERNANDES, P. D.; GHEYI, H. R.; DANTAS NETO, J. Qualidade industrial de cana-deaçúcar sob irrigação e adubação com zinco, em tabuleiro costeiro paraibano. Revista Brasileira de Engenharia Agricola e Ambiental, Campina Grande, v. 13, n. 4, p. 419-428, 2009.

FERREIRA, D. F. SISVAR: um programa para análises e ensino de estatística. Revista Symposium, Lavras, v. 6, n. 2, p. 36-41, 2008.

FRANCO, H. C. J.; TRIVELIN, P. C. O.; VITTI, A. C.; FARONI, C. E.; SARTORI, R. H. Produtividade e atributos tecnológicos da cana-planta relacionados à aplicação de zinco. STAB - Açúcar, Álcool e Subprodutos, Piracicaba, v. 27, n. 5, p. 30-34, 2009.

HOFFMANN, H. P. (Ed.). Variedades RB de cana-deaçúcar. Araras: CCA/UFSCar, 2008. 30 p.

KORNDÖRFER, G. H.; BENEDINI, M. S.; ROCHA, A. C. da; FERREIRA NETO, D. A. Avaliação de três variedades de cana (Saccharum officinarum) submetidas a adubação com micronutrientes. STAB - Açúcar, Álcool e Subprodutos, Piracicaba, v. 14, n. 1, p. 23-26, 1995. 
KORNDÖRFER, G. H.; RIBEIRO, A. C.; ANDRADE, L. A. B. Cana-de-açúcar. In: RIBEIRO, A. C.; GUIMARÃES, P. T. G.; ALVAREZ, V. H. (Ed.). Recomendações para o uso de corretivos e fertilizantes em Minas Gerais. 5. ed. Viçosa: Comissão de Fertilidade do Solo do Estado de Minas Gerais, 1999. p. 285-288.

MALAVOLTA, E.; VITTI, G. C.; OLIVEIRA, S. A. Avaliação do estado nutricional de plantas: princípios e aplicações. 2. ed. Piracicaba: Potafos, 1997. 308 p.

MARINHO, M. F.; ALBUQUERQUE, G. A. C. de. Efeitos do cobre e do zinco na produção de canade-açúcar em solos de tabuleiros de Alagoas. Brasil Açucareiro, Rio de Janeiro, v. 98, n. 6, p. 41-50, 1981.

MORAES, M. F. de; SANTOS, M. G.; BERMÚDEZZAMBRANO, O. D.; MALAVOLTA, M.; RAPOSO, R. W. C.; CABRAL, C. P.; MALAVOLTA, E. Resposta do arroz em casa de vegetação a fontes de micronutrientes de diferentes granulometria e solubilidade. Pesquisa Agropecuária Brasileira, Brasília, v. 39, n. 6, p. 611-614, 2004.

ORLANDO FILHO, J.; ROSSETO, R.; CASAGRANDE, A. A. Cana-de-açúcar. In: FERREIRA, M. E. Micronutrientes e elementos tóxicos na agricultura. Jaboticabal: CNPq/FAPESP/POTAFOS, 2001. v. 1, p. 355-373.
RAIJ, B. van; ANDRADE, J. C.; CANTARELLA, H.; QUAGGIO, J. A. Análise química para avaliação da fertilidade de solos tropicais. Campinas: IAC, 2001. 285 p.

RAIJ, B. van; CANTARELlA, H.; CAMARGO, C. E. O. Outras culturas industrais. In: RAIJ, B. van; CANTARELlA, H.; QUAGGIO, J. A.; FURLANI, A. M. C. Recomendações de calagem e adubação para o Estado de São Paulo. Campinas: IAC, 1997. p. 233-239 (Boletim técnico, 100).

RIPOLI, T. C. C.; RIPOLI, M. L. C. Biomassa de canade-açúcar: colheita, energia e ambiente. 2. ed. Piracicaba: Edição dos autores, 2004. 202 p.

SEGATO, S. V.; ALONSO, O.; LAROSA, G. Terminologias no setor sucroalcooleiro. In: SEGATO, S. V.; PINTO, A. S.; JENDIROBA, E.; NÓBREGA, J. C. M. Atualização em produção de cana-de-açúcar. Piracicaba: CP 2, 2006. p. 397-405.

TAIZ, L.; ZEIGER, E. Fisiologia vegetal. 3. ed. Porto Alegre: Artmed, 2004. 719 p.

WANG, J. J.; KENNEDY, H. P.; VIATOR, H. P.; ARCENEAUX, A. E.; GUIDRY, A. J. Zinc fertilization of sugarcane in acid and calcareous soils. Journal of the American Society of Sugar Cane Technologists, Florida, v. 25, n. 1, p. 49-61, 2005. 